\title{
Numerical and Experimental Study on Proposed T-Form Semi-Precast Moment-Resisting Concrete Connections
}

\author{
Mojtaba Fathi $1^{* 1 a}$, Mahdi Parvizi ${ }^{\text {1b }}$ \\ ${ }^{1}$ Engineering Faculty, Department of Civil Engineering, Razi University, Kermanshah, Iran
}

\begin{abstract}
This paper presents the results of experimental and numerical study on a proposed exterior semi-precast moment-resisting concrete connection. Steel linkage element connects precast concrete beam to column in two cases of bolted and welded connections. These connections were compared to monolithic connection based on stiffness, strength, energy dissipation capacity and ductility factor. An accurate 3D nonlinear finite element model has been simulated to study the behavior of these connections. A good agreement was observed between numerical results and experimental ones in behavior and damage mode. Although, all samples satisfied all the code criteria, but the trend of failure in bolted and welded connection was observed on the weld and bolts area, at the connection zone between beam and steel linkage. However, in monolithic connection, the yielding was observed in rebars and crushing of concrete at the end of beam. The initial stiffness of bolted and welded connection specimen was less than that of monolithic connection specimen. But, the beam moment capacity factors of these samples were a little more than monolithic sample; so, the ductility factors of them were a little less than that of monolithic sample.
\end{abstract}

Keywords: Experimental Study; Precast Concrete Frame; Moment-Resisting Connection; Hybrid Connection; Cyclic Loading; Finite Elements Analysis

\section{Introduction}

Precast technology is a way to construct reinforced concrete structures. Precast structures possess various privileges like: high quality control, economical cost, and speed on erection. One of the most significant parameters in seismic behavior of precast structures, is the quality of precast elements connection to each other. Precast concrete structures are usually used as a simple frame with simple connection of beam to column and cast-in-place shear wall. Many researches have been conducted concerning connections in precast structures within the last decades. Ertas et al [1] did a series of tests on precast frame. They developed many models by using cast-in-place concrete in the beam-column connection. Senel and Kayhan [2] undertook a case study to investigate the fragility of precast building based on damage assessment by using non-linear time history analysis. Negro et al [3] and Bournas et al [4] conducted pseudo-dynamic tests on a full-scale 3-storey precast concrete building. A good behavior of a precast concrete system was shown by the study. Choi et al [5] using embedded steel end plates in beam and column, proposed precast concrete beam-to-column connection. The performance of the joint was measured according to connection strength, stiffness, energy dissipation, and drift capacity. Shariatmadar and Zamani [6] introduced three kinds of precast concrete connection with different details that are, straight spliced, U-shaped and U-shaped with steel plate. The behavior of the first one was similar to monolithic connection. Zoubek et al [7] proposed a nonlinear finite element model of centric dowel connections in precast buildings. They included several material and interaction parameters and studied their effects. Vidjeapriya et al [8] used precast concrete connection in a way that beam is connected to column with corbel using (i) dowel bar and (ii) dowel bar with cleat angle. Concerning ductility, a better

*Corresponding author, Assistant Professor, E-mail: fathim@ @azi.ac.ir, Tel:+988334274530, Postal code: 6714967346

${ }^{a}$ Ph.D Student, E-mail: civil.parvizi@gmail.com 
behavior compared to the monolithic specimen was observed in precast specimens with dowel bar and cleat angle. Kataoka et al [9] by conducting a numerical and experimental study, investigated the behavior of a specific type of beam-column connection. This kind of connection was composed of concrete corbels, dowels and continuity bars passing through the column. Yuksel et al [10] investigated two types of exterior beam-column precast connection, for residential and industrial joints, numerically. Dry and wet instalment techniques were used. These connections showed stable load-displacement hysteresis curve and high dissipation energy up to $2 \%$ drift and showed high level of pinching about 3\% drift. Guan et al [11] proposed a novel beam to column connection by doing an experimental study. The suggested connection, showed good seismic resistance, hysteretic behavior, strength, deformability, stiffness, and energy dissipation. Fleischman and Seeber [12] discussed precast- prestressed concrete structures for developing countries. That lead to advantages in resilience and sustainability. Aninthaneni and Dhakal [13] presented the concept of a next-generation building system. The proposed structural system included standard precast-concrete $\backslash$ components and removable dry steel connections. They provided schematic details of the structural system and possible dry steel connections. Fathi et al [14] proposed semi-precast rigid concrete connection by a steel linkage. Two types of welded and bolted connections were tested under cyclic loading. The results satisfied all criteria of ACI T1.1-01 [15]. Bahrami et al [16] studied two new moment resisting precast connection, numerically. In this connection precast beam was connected to the precast column with corbel by use of (i) inverted Ebolted connection and (ii) by box section- welded connection. Lateral resistant, ductility and lateral stiffness were $98 \%, 80 \%$ and $80 \%$ monolithic connection. Yan et al [17] studied seismic behavior of precast connections, experimentally. The column, joint and a part of beam away from the joint was precast while a part of beam near to the joint was cast in place. Rebars were connected by grout sleeves. Behavior of this precast connection was similar to monolithic one. However, crack distribution, strain of rebars and deformation of joint were different. Lago et al [18] proposed an innovative structural frame system for dry-assembled hinge joint. This study was based on adaptation of hinge joints in to the rigid connection, by activation of some mechanical devises in connection zone. The results of non-linear dynamic analysis showed the good performance of this solution. Fahfi and Afreydoun [19] reported the test results of a series of T-form precast frames under cyclic loading. Two beam- column connection were semi- precast rigid and third one was monolithic. This paper is based on these results.

In the field of precast technology, the major part of research activities was done by NIST [20] in the US, however, implementation of post-tension cables with mild steel or hybrid connection was the central idea of their proposed connections. The committee formed its actions into four phases. In each phase the tests were planned and managed taking into account the defects in the previous phase to enhance the connection behavior. The experiments had various components and variables such as: the amount of mild steel, location of post-tensioned cables and the post-tensioning force. A type of connection system for moment-resisting precast concrete frames has been proposed in this study. This connection is composed of steel linkage element that is connected to the column by bolts and to the beam by bolts or welding. In this way concrete structures are made with better quality than cast-in-place structures through minimizing in-situ concreting, maximizing the speed of construction and usage of ductile and exchangeable elements in sensible locations of the connection. Also by using ABAQUS software, the 3D finite element models of these connections are developed to make the behavior of this type of connection predictable. Then the results of numerical and experimental studies are compared to each other.

\section{Test Procedure}

Fig. 1 shows the cross section of beam and column. In table 1 the mechanical properties of the material have been shown. The design of all specimens was done based on ACI 318-05 [21] code provisions. For all specimens, the column's longitudinal reinforcement ratio was $2 \%$, and spacing of the closed stirrups was almost $10 \mathrm{~cm}$. The diameter of longitudinal bars were $20 \mathrm{~mm}$ and for stirrups was $10 \mathrm{~mm}$. 
The specimens came out to be BC (Bolted Connection), WC (Welded Connection) and MC (Monolithic Connection). The connection of beam to the precast column by means of a steel linkage element was the main idea for construction of $\mathrm{BC}$ and WC. Therefore at the beginning, the steel linkage was made of $10 \mathrm{~mm}$ thickness plates by welding technique and all welds were tested with Ultrasonic Test (UT) to guarantee welding quality. Embedded threaded bolts connected steel linkage to precast column. The bolts were composed of A325 steel with the strength of $F_{u}=800 \mathrm{MPa}$.

Beams construction is done in two stages. First is the lower half of the beam which is made in factory in the form of precast. Then the half-beam was connected to the steel linkage with nuts and washers for the $\mathrm{BC}$ sample. It was also connected with bars welded to the end of the beam and aiding steel element to the steel linkage element in the WC sample. In the second stage, the upper half-beam was constructed in-situ and after fastening the stirrups to the reinforcements, the upper half beam was concreted along with the slab and the concrete frame was completed. Fig.2 demonstrates the details of the three samples.

The test setup was designed to apply the procedure and scheme specified in the ACI T1.1-01. The procedure and scheme specified in the ACI T1.1-01 were applied by designing the test setup (Fig. 3). The precast concrete column was supported on a pinned support at base, a roller-supported "hinge end" was designed for the beam and the top of the column was free to move and rotate.

Axial load was not applied to the column. Two hydraulic actuators were used. While one of the actuators was away from the beam, the other imposed load. After imposing a proper level of load, the hydraulic pressure of the first actuators was discharged, and the second actuator imposed the load to the beam in opposite direction. The lateral load was gradually increased to reach the predetermined story drift. To prevent the beam and the column out of the frame movement, some lateral bracings were installed. Vertical displacement at the beam end was measured by using a linear potentiometer mounted at the level of the hydraulic actuators.

Considering the ACI T1.1-01, the following loading pattern (displacement) was chosen to be applied to the specimens (Fig. 4).

\section{Finite Element Modeling and Analysis}

The finite element software ABAQUS was used to model and analyze the mentioned samples. The effects of nonlinearity of material, geometry and contact between different parts of the model as well as bond-slip effect of reinforcement bars have been considered. Fig. 5 shows the FE (Finite Element) model.

Eight-node 3D solid element with reduced integration (C3D8R) and four node tetrahedral 3D solid elements (C3D4) were used to simulate the concrete and steel linkage, respectively. For the reinforcing bars, two types of element were considered. At the end of rebar that leads to weld or bolt for the application of interaction between rebar and linkage, and for the upper reinforcing bars of beam for considering bond slippage of them in column, using 3D elements C3D8R is a necessity. For other cases 3D two-node elements (B31) were used. The approximate mesh size of beam and column, steel linkage and bars were $80 \mathrm{~mm}, 40 \mathrm{~mm}$ and $50 \mathrm{~mm}$, respectively. It should be noted that for regions with irregular geometry, finer mesh was used. Finally total number of 10699 elements for BC specimen, 11341 elements for WC specimen and 4587 elements for MC specimen were used.

To simulate the behavior of steel materials as they are subjected to cyclic loading, a linear kinematic hardening model was used. In this model, stress-strain curve of steel materials is bilinear and the slop of second part was chosen as $0.01 E$ [22]. The elastic modulus of $2.1 \times 10^{5} \mathrm{MPa}$ and 
Poisson's ratio of 0.3 were defined. To simulate the concrete behavior under cyclic loading, Concrete Damage Plasticity Model has been used. This model is composed of both compressive and tensile stress-strain curve and their corresponding damage parameters.

The proposed equation by Hognestad [23] was used for compressive stress- strain behavior. Eq. (1) to Eq. (3) state the compressive stress-strain curve. The Poisson's ratio of 0.2 was considered for concrete.

$$
f_{c}=f_{c}^{\prime}\left(2 \frac{\varepsilon_{c}}{\varepsilon_{c 0}}-\left(\frac{\varepsilon_{c}}{\varepsilon_{c 0}}\right)^{2}\right) \quad \varepsilon \leq \varepsilon_{0}
$$

$$
f_{c}=f_{c}^{\prime}\left(1-0.15\left(\frac{\varepsilon-\varepsilon_{0}}{\varepsilon_{c u}-\varepsilon_{0}}\right)\right) \quad \varepsilon_{0} \leq \varepsilon \leq \varepsilon_{1}
$$

$$
f_{c}=0.2 f_{c}^{\prime} \quad \varepsilon_{1} \leq \varepsilon
$$

(3)

And for tensile behavior Eq. (4) and Eq. (5) [23] were used.

$f_{t}=E_{c} \varepsilon \quad \varepsilon \leq \varepsilon_{t}$

$$
f_{t}=\lambda f_{c}^{\prime}\left(1-\frac{\varepsilon-\varepsilon_{t}}{\varepsilon_{m}-\varepsilon_{t}}\right) \quad \varepsilon_{t} \leq \varepsilon
$$

(5)

This model contains the degradation of both tension and compression stiffness.

Damage parameter has been computed by Eq. (6) and Eq. (7) [24]:

$$
d_{t}=1-\frac{\left(f_{t}+n_{c} f_{t 0}\right)}{E_{c}\left(n_{t} f_{t 0} / E_{c}+\varepsilon_{t}\right)}
$$

$$
d_{c}=1-\frac{\left(f_{c}+n_{c} f_{c}^{\prime}\right)}{E_{c}\left(n_{c} f_{c}^{\prime} / E_{c}+\varepsilon_{c}\right)}
$$

Where $f_{t}$ is tensile stress, $f_{c}$ is compressive stress, $f_{t 0}$ is tensile strength, ${ }_{c}{ }^{\prime}$ is compressive strength, $E_{c}$ is module of elasticity of concrete, $\varepsilon_{t}$ is tensile strain, $\varepsilon_{c}$ is compressive strain, ${ }_{t}=1$ and $n_{c}=2 \quad$ [24].

For tangential behavior, a cohesive model and penalty contact method with friction coefficient of 0.1 , and for normal behavior, a hard contact model have been used. The friction model activates when the cohesive stiffness starts to degrading [25].

By means of progressive damage concept, bond slip was modeled. Damage as a mechanism, includes two steps in this method: first, defining damage initiation criterion and then introducing a criterion for continuing damage after passing from this initiation point. The simulation of the cohesive between reinforcements and concrete and corresponding progressive damage has been done according to researches conducted by Delso et al [26]. The damage model has been simulated according to Fig. 6.

The degradation process begins when the contact stresses reaches to a certain damage initiation criteria that has been specified by user. Initiation of damage refers to the beginning of degradation of the cohesive stiffness at a contact point. The damage evolution law describes the rate of stiffness degradation once the corresponding initiation criterion is reached [25]. 
In this study, according to the recommended values of $\tau_{\max }, S_{\text {peak }}$ and $S_{R}$ by Delso et al [26], when the shear stress reaches to $\tau_{\max }=15 \mathrm{MPa}$ tangential damage initiates and $1.5 \mathrm{~mm}$ and $12 \mathrm{~mm}$ have been considered for $S_{\text {peak }}$ and $S_{R}$, respectively.

According to the test results of concrete specimens, the average of compressive strength was $35 \mathrm{MPa}$ and the ultimate tension stress of concrete was considered by $10 \%$ of ultimate compressive strength. Adopted mechanical properties of steel materials have been presented in Table 1 .

As it is shown in Fig. 3, the end of column and the end of beam have been defined as hinge and roller, respectively.

\section{Evaluation of Test and Numerical Results}

The lateral force versus the story displacement of the specimens for both experimental and numerical results have been shown in Fig. 7. The behavior of specimens in the initial cycles of loading was linear elastic. First crack and then more cracks occurred in the specimens as the loading proceeds; then, the samples passed the ideal level code. Since no loss of strength was observed during these steps, the tests were continued to study the behavior in more displacements. The MC, BC and WC specimens were compared according to their stiffness, strength and energy dissipation properties.

The hysteresis curves of samples especially BC and WC samples are in a way that the curves possess a pinching and residual displacement because of crack opening and closing during the loading reversals, as well as the interactions among the axial load, shear forces, and bending moments and also lack of appropriate interaction between the concrete and the internal surface of the groove at the upper half of beam. To come to better comparison between experimental and numerical result, the force-displacement curve of $1.5 \%, 2 \%, 3 \%, 4 \%$ and $5 \%$ drift, have been plotted individually. It depicts the precision of simulation more accurately.

It can be seen that finite elements method results and test results are in good accordance with each other. The maximum error percentage of peak strength is about $5 \%$. The little difference between the FE and experimental results at different stages of loading can be attributed to mesh refinement, idealized boundary conditions in the FE model, material nonlinearity, and particularly the way of defining parameters in contact points.

\subsection{Mechanical characteristics of specimens}

The envelope curves of the specimens in Fig. 7 measure their strength (bearing lateral load capacity). The envelope curves were obtained by connecting the maximum points in load-drift ratio diagram. The value of maximum and ultimate resistance and displacement have been provided in Table 2. The results show that WC and MC specimens have higher and lower resistance, respectively. As we know welded connection has high rigidity but brittle behavior. So, it is expected that WC specimen have higher resistance but lower ductility.

The ratio of ultimate strength to maximum strength $(\alpha)$ and initial stiffness $(I S)$ of each specimen, have been provided in Table 2. It is obvious that the initial stiffness of MC specimen has greater value than others and $\mathrm{BC}$ specimen is stiffer than $\mathrm{WC}$ specimen.

Displacement ductility factor, one of the criteria of nonlinear behavior of frame subjected to cyclic loading, is defined as the ratio of displacement at the maximum load $\left(\delta_{\max }\right)$ to displacement at the yield load $\left(\delta_{y}\right)$ as expressed by Eq. (8):

$\mu=\frac{\delta_{\max }}{\delta_{y}}$ 
The ratio of beam moment capacity $(\Omega)$ is calculated by Eq. (9):

$\Omega=\frac{\text { Experimental beam moment capacity }}{\text { Design beam moment capacity }}$

It should be noted that, the design beam capacity was calculated by using typical procedure of RC beam design and according to ACI318-05 code. Considering mentioned property of materials, 110 $\mathrm{kN}$.m was resulted for all of specimens. For the experimental beam moment capacity, maximum recorded load multiplied by the distance between hydraulic jack and column face. The values of $\mu$ and $\Omega$ are given in Table 2 . The beam capacity factor $(\Omega)$ for BC and WC specimens is bigger than that for MC specimen, and this is vice versa for the ductility factor $(\mu)$.

This is justified by high stiffness of the steel linkage and low ductility of bolted and welded connections in $\mathrm{BC}$ and $\mathrm{WC}$ specimens.

The ACI T1.1-01 code as an acceptance criteria, determines that the strength loss of the specimens should not be more than $25 \%$ of the maximum strength. The results shows that this criteria is satisfied.

\subsection{Energy Dissipation Capacity}

Based on the ACI T1.1-01, for a given cycle, the relative energy dissipation ratio $\beta$, is the area inside the lateral force-drift ratio loop for the module $\left(A_{h}\right)$, divided by the area of the effective circumscribing parallelograms $\mathrm{ABCD}$ and $\mathrm{DFG}\left(A_{2}\right)$. The areas of the parallelograms equal the sum of the absolute values of the lateral force strengths, $E_{1}$ and $E_{2}$, at the drift ratios, $\theta_{1}$ and $\theta_{2}$, multiplied by the sum of the absolute values for the drifts ratios, $\theta_{1}^{\prime}$ and $\theta_{2}^{\prime}$ (Fig. 8).

As described above, the relative energy dissipation ratio concept was calculated from the last cycle of each successive story's drift ratio.

Fig. 9 shows the relative energy dissipation ratio versus the drift ratio for the specimens both experimentally and numerically.

The acceptance criterion of the ACI T1.1-01 code requires that the relative energy dissipation ratio should not be less than 0.125 . It is observed that this criteria is satisfied.

\subsection{Stiffness Degradation}

For comparing the stiffness degradation of the specimens, the secant stiffness ( $\left.K_{\mathrm{sec}}\right)$ calculated at the last cycle of each successive story's drift level was used. The secant stiffness is defined as the slope of the straight line between the maximum drift levels of that specific load cycle. It is also called "peak-to-peak stiffness". With respect to the initial secant stiffness of the specimen, each secant stiffness value of a specific specimen was normalized. For this purpose, the stiffness degradation of specimens versus story drift for numerical and experimental results is plotted in Fig.10. The accuracy of numerical result is good and the maximum error percentage of point to point is less than $6 \%$.

The ACI T1.1-01 code requires that the secant stiffness from a drift ratio of -0.0035 to a drift ratio of +0.0035 should not be less than 0.05 times the stiffness for the initial drift ratio. Fig. 10 shows that the energy criteria of ACI T1.1-01 code is satisfied. 


\subsection{Behavior of Contacts}

To evaluate the accuracy of numerical simulation in predicting the behavior of connections, some failure modes and deformation shapes predicted by the model, have been compared with what was observed in the experiments. Deformation of the model in BC type connection has been shown in Fig. 11. A gap between concrete and steel linkage, and also between concrete beam and column at contact points have been predicted that can be seen in the test too. At these points, according to the test observation, contact properties have been described well, at which they act only at compression and allow separation at tension.

\subsection{Pattern of Damage}

One of the best methods to show the real behavior of specimens is the crack distribution pattern. There is no significant difference between the damages in specimens in the initial steps of the loading. Cracks in monolithic specimen move toward the center of the beam due to an increase in the shear stress at the end of the beam, as the load increases. Due to high stiffness and strength of the linkage in these tests, no damage took place in the linkage and all damages occurred in the concrete beams near the steel linkages. Almost in all specimens, the first crack took place at the end of the beam in cycles 7 and 9. As the loading continues in cycles 14 and 15, corresponding to $0.35 \%$ drift, the cracks are mostly vertical. After that, the cracks develop to the center of the beam section; ultimately, they find a diagonal form and tend toward the panel zone. In BC and WC samples as the load increases, however, some cracks are created around the steel linkage. Also, at the top of the beam section, because of slipping of the concrete from the sleeve, the bearing cracks cause the concrete to be crushed. Fig. 12 depicts the crack patterns of the specimens in finite element models. In FE model, the direction of normal vector to the crack plane is assumed to be parallel to the direction of maximum principal plastic strain. The red vectors show the maximum principal plastic strain directions. There is a good agreement between fracture modes predicted by finite element analysis and experimental observations.

\section{Conclusion}

In this research, a type of semi-precast exterior ductile connection was suggested and studied numerically and experimentally in order to be used in moment-resisting precast concrete frames. So, two bolted and welded specimens of the proposed connections were made and constructed as well as a monolithic specimen in full scale. Then they were tested under reversed cyclic loading according to the ACI T1.1-01. The capacity of BC, WC and MC specimens were $128 \mathrm{kN}, 136 \mathrm{kN}$ and $104 \mathrm{kN}$ and the ductility factors were 3.42, 2.7 and 6.2, respectively. Also, damage pattern of cracks showed that the proposed connection can be used in precast moment-resisting concrete frames. This investigation on the proposed connections showed that, although in these type of connection precast beams and columns are connected by a steel linkage, they satisfy all the code criteria and have higher strength than monolithic connection but lower displacement ductility factor.

\section{Acknowledgements}

Financial aids of Eisar Gharb Company, especially the personnel of the production line during the manufacturing and production are warmly appreciated. 


\section{References}

[1] Ertas, p., Ozden, S. and Ozturan, T. "Ductile Connections in Precast Concrete Moment Resisting Frames", PCI., 51(3), pp. 66-76 (2006).

[2] Senel, S.M. and Kayhan, A.H. "Fragility based damage assesment in existing precast industrial buildings: A case study for Turkey", Structural Engineering and Mechanics., 34(1), pp. 39-60 (2010).

[3] Negro, p., Bournas D.A. and Molina, F.J. "Peseudo Dynamic Tests on a Full-Scale 3-Story Precast Concrete Building Global Response", Engineering Structures., 57(4), pp. 594-608 (2013).

[4] Bournas, D.A., Negro P. and Molina, F.J. "Peseudo Dynamic Tests on a Full-Scale 3-Story Precast Concrte Building: Behavior of the Mechanical Connections and Floor Diaphragms", Engineering Structures., 57(4), pp. 609-627 (2013).

[5] Choi, H.K., Choi, Y.C. and Choi, C.S. "Development and testing of precast concrete beam-tocolumn connections", Engineering Structures., 56, pp. 1820-1835 (2013).

[6] Shariatmadar, H. and Zamani Beydokhti, E. "An Invesigation of Seismic Response of Precast Concrete Beam to Column Connections: Experimental Study", Asian Journal of Civil Engineering., 15(1), pp. 41-59 (2014).

[7] Zoubek, B., Fahjan, Y., Fischinger, M. and Isakovic, T. "Nonlinear finite element modelling of centric dowel connections in precast buildings", Computers and Concrete., 14(4), pp. 463-477 (2014).

[8] Vidjeapriya, R., Vasanthalakshmi, V. and Jaya, K.P. "Performance of exterior precast concrete beam-column dowel connections under cyclic loading", International Journal of Civil Engineering., 12(1), pp. 82-95 (2014).

[9] Kataoka, M.N. Ferreira, M.A. and El Debs A.L.H.C. "Study on the behavior of beam-column connection in precast concrete structure", Computers and Concrete., 16(1), pp. 163-178 (2015),

[10] Yuksel, E., Karadogan, F.H., Bal, E.I.,Ilki, A., Bal, A. and Inci, P. "seismic behavior of two exterior beam-column connection made of normal-strenght concrete developed for precast contruction", Engineering Structures, 99, pp. 157-172 (2015),.

[11] Guan, D., Guo, Z., Xiao, Q. and Zheng, Y. "Experimental study of a new beam-to-column connection for precast concrete frames under reversal cyclic loading", Advances in Structural Engineering., 19(3), pp. 529-545 (2016).

[12] Fleischman , R.B. and Kim Seeber, P.E. "New construction for resilient cities: The argument for sustainable low damage precast/prestressed concrete building structures in the 21 st century", Internatinal Journal of Scientia Iranica, 23(4), pp. 1578-1593 (2016).

[13] Aninthaneni, P.K. and Dhakal, R.P. "Demountable precast concrete frame building system for seismic regions: conceptual development", Journal of Journal of Architectural Engineering, 23(4), 1593 (2017).

[14]Fathi, M., Parvizi, M., Karimi, J. and Afroedoun, M.H. "Experimental and Numerical Study on a Proposed Moment-Resisting Connection for Precast Concrete Frames", Internatinal Journal of Scientia Iranica, 25(4), pp.1977-1986 (2018).

[15] ACI T1.1-01. "Acceptance Criteria for Moment Frames Based on Structural Testing", Reported by ACI Innovation Task Group 1 and Collaborators, (2001)

[16] Bahrami, S., Madhkhan, M., Shirmohammadi, F. and Nazemi, N. "Behavior of two new moment resisting precast beam to column connections subjected to lateral loading", Engineering Structures, 132, pp.808-821 (2017).

[17] Yan, Q., Chen, T. and Xie, Z. "Seismic experimental study on a precast concrete beamcolumn connection with grout sleeves", Engineering Structures, 155, pp.330-344 (2018).

[18] Lago, B.D., Negro, P. and Lago, D.A. "Seismic design and performance of dry-assembled precast structures with adaptable joints", Soil Dynamics and Earthquake Engineering, 166, pp.182-195 (2018).

[19] Fathi, M. and Afroedoun, M.H. "Experimental study of a new rigid connection for precast concrete structures", Ministry of science, research and technology, Razi university, Engineering faculty, (2013) 
[20] Geraldine, S.C., William C.S. and Nakaki, S.D. "Simplified Design Procedure for Hybrid Precast Concrete Connections", National Institute of Standard and Technology, (1996),

[21] ACI Committee 318, "Building code requirements for structural concrete (318-05) and commentary-(318R-05)", ACI, Farmington Hills, Michigan (2005).

[22] Han, L.H and Li, W. "Seismic performance of CFST column to steel beam joints with RC slab: Analysis", Journal of Constructional Steel Research., 67, pp. 127-139 (2011).

[23] Akhaveissy, A.H. and Desai, C.S. "Application of the DSC model for nonlinear analysis of reinforced concrete frames", Finite Elements in Analysis and Design., 50, pp. 98-107 (2012).

[24] Pagoulatou. M, Sheehan. T, Dai. X.H and Lam. D. "Finite element analysis on the capacity of circular concrete-filled double-skin steel tubular (CFDST) stub columns" , Journal of Engineering Structures., 72, pp. 102-112, (2014).

[25] Simulia Inc. "ABAQUS Standard (Abaqus/ CAE 2018)" (2018),.

[26] Murcia-Delso. J, Stavridis. A, and Shing. B. "Modeling the bond-slip behavior of confined large diameter reinforcing bars" , III ECCOMAS Thematic Conference on Computational Methods in Structural Dynamics and Earthquake Engineering., Corfu, Greece (2011).

\section{Figure Captions:}

Fig. 1 Assembling of precast specimens

Fig. 2 Details of specimens and steel linkages

Fig. 3 Test setup

Fig. 4 Applied loading Pattern

Fig. 5 Finite element modeling

Fig. 6 Damage evolution of cohesive behavior [26]

Fig. 7 Hysteresis curve of specimens

Fig. 8 Relative energy dissipation ratio concept

Fig. 9 Relative energy dissipation of specimens

Fig. 10 Stiffness degradation of specimens

Fig. 11 Deformation shapes in contact points in FEM and corresponding behavior in test

Fig. 12 Comparison of crack pattern in specimens and prediction of cracks in finite element models

\section{Tables Captions:}

Table 1 Mechanical property of materials

Table 2 Mechanical characteristics of specimens

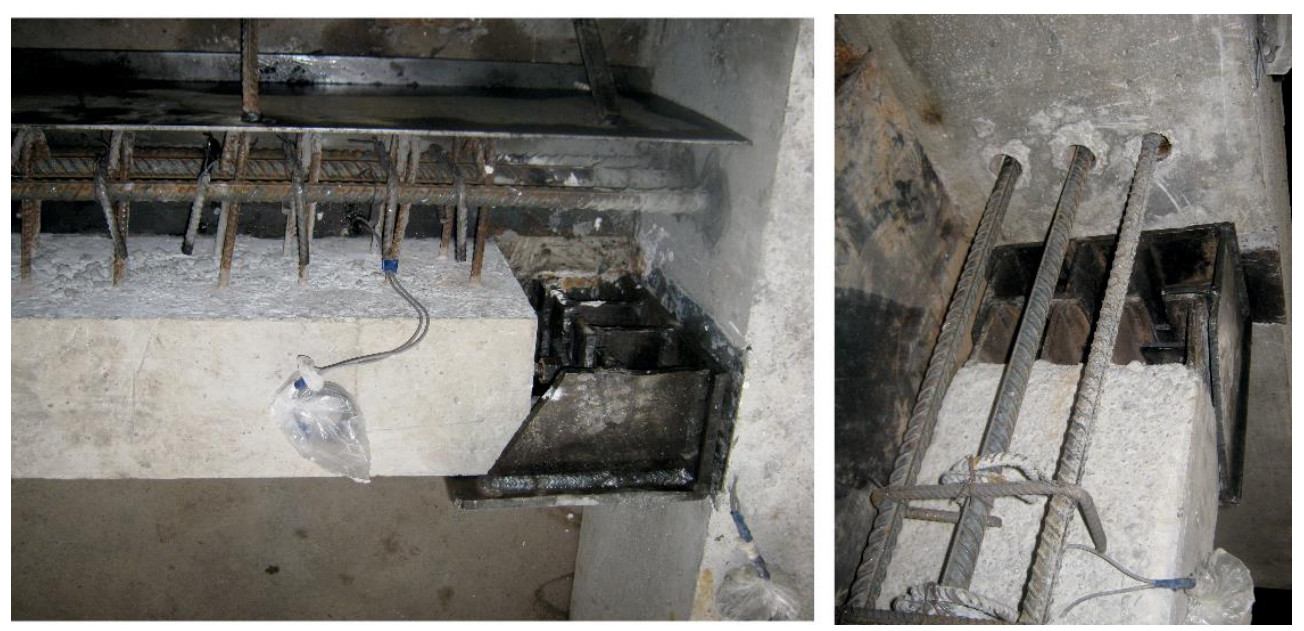

Fig. 1 Assembling of precast specimens 


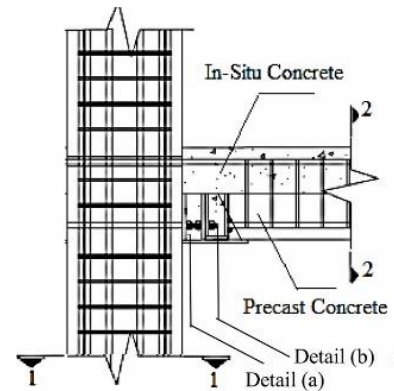

B. WC Specimen
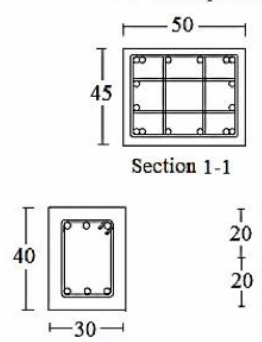

Section 3-3

D. Beam and Column Sections

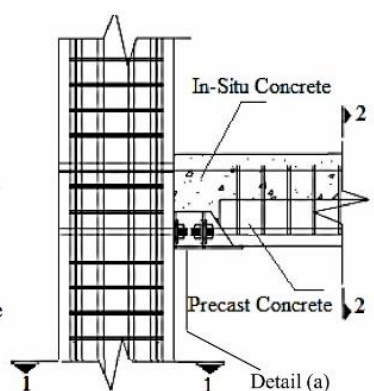

A. BC Specimen

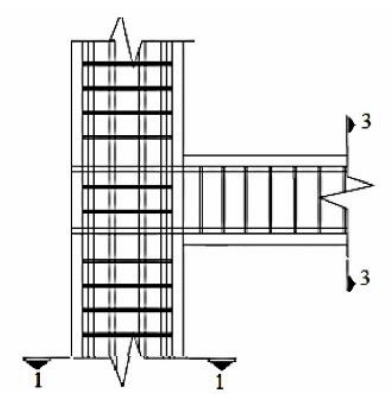

C. MC Specimen

Fig. 2 Details of specimens and steel linkages

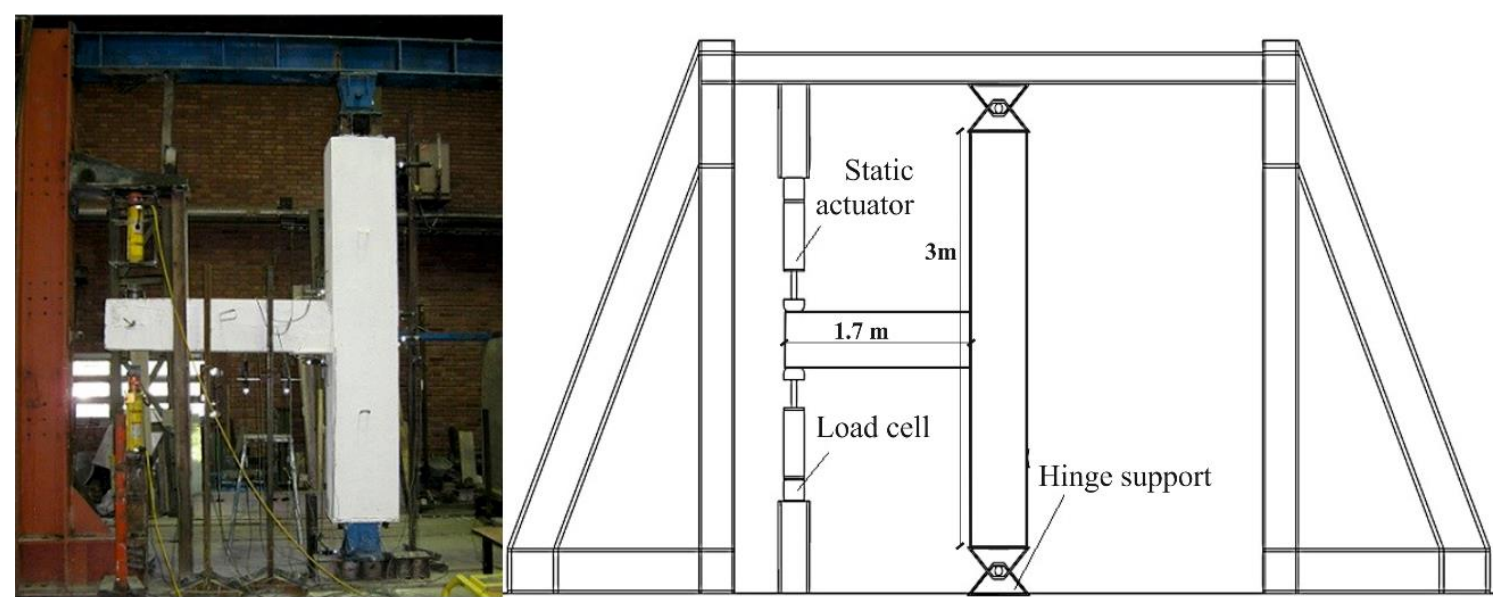

Fig. 3 Test setup

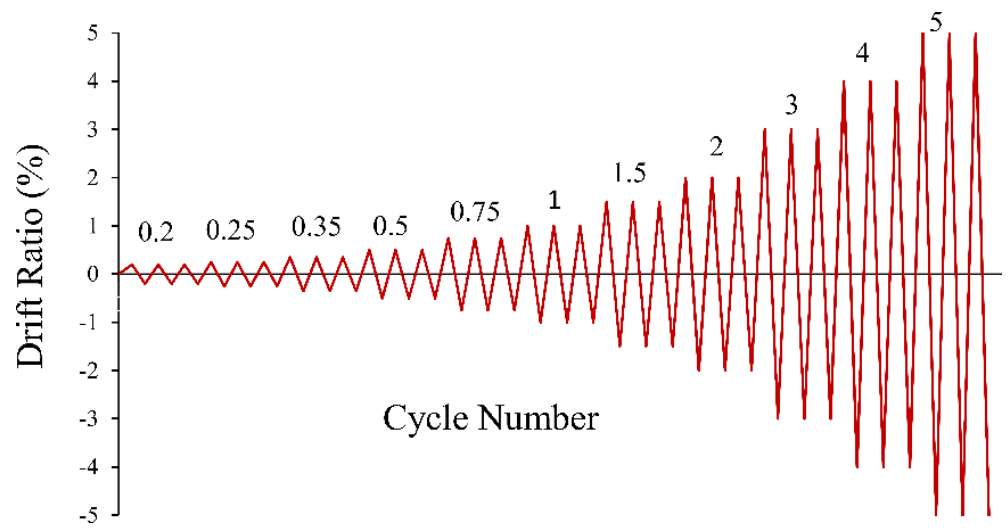

Fig. 4 Applied loading Pattern 


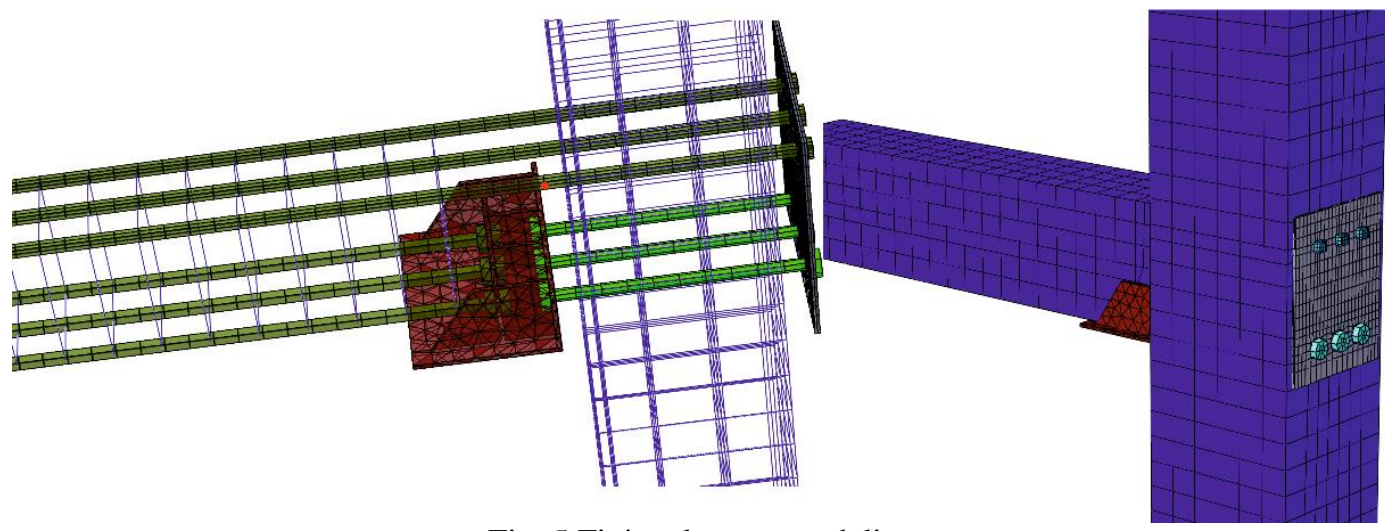

Fig. 5 Finite element modeling

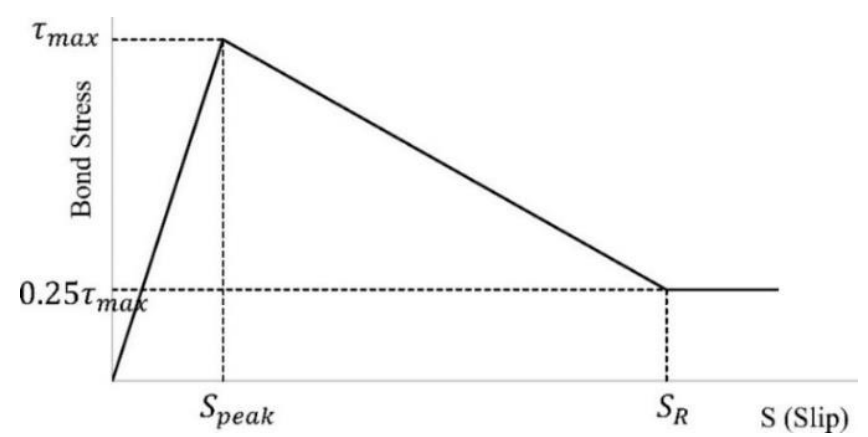

Fig. 6 Damage evolution of cohesive behavior [26] 

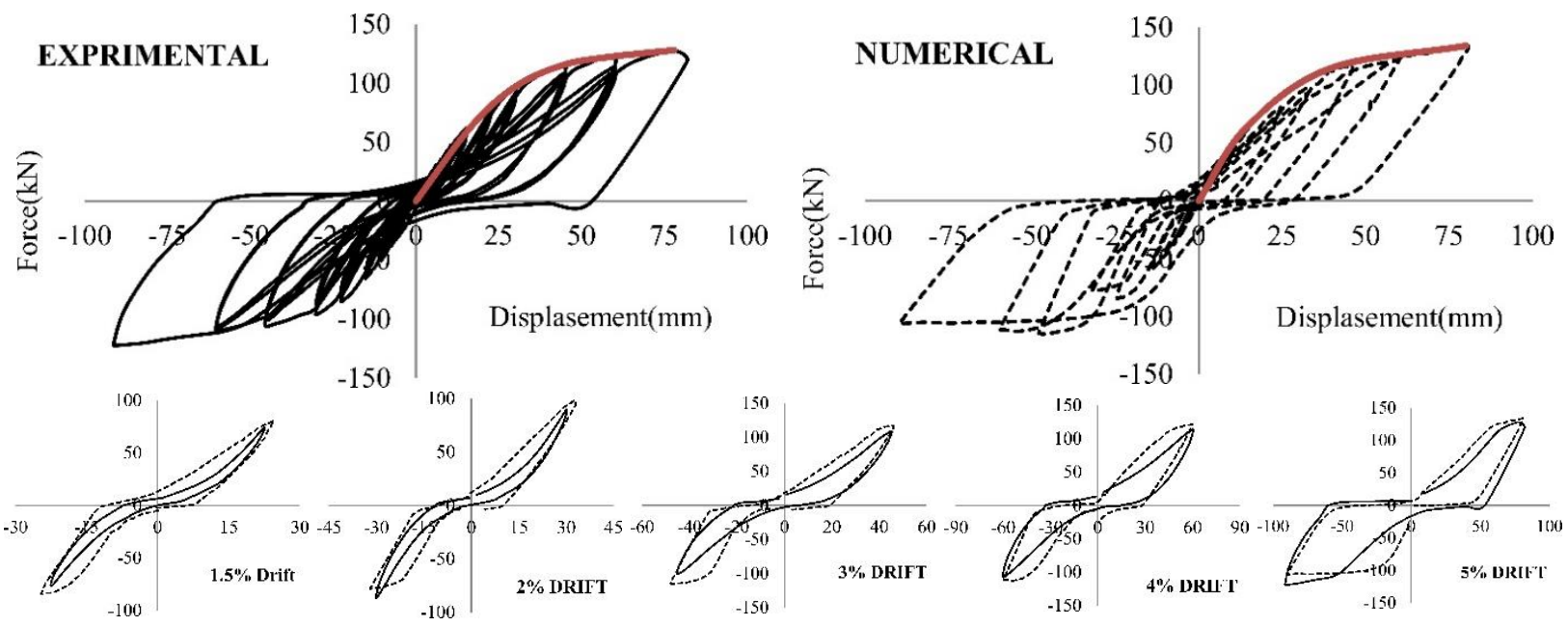

BC Specimen
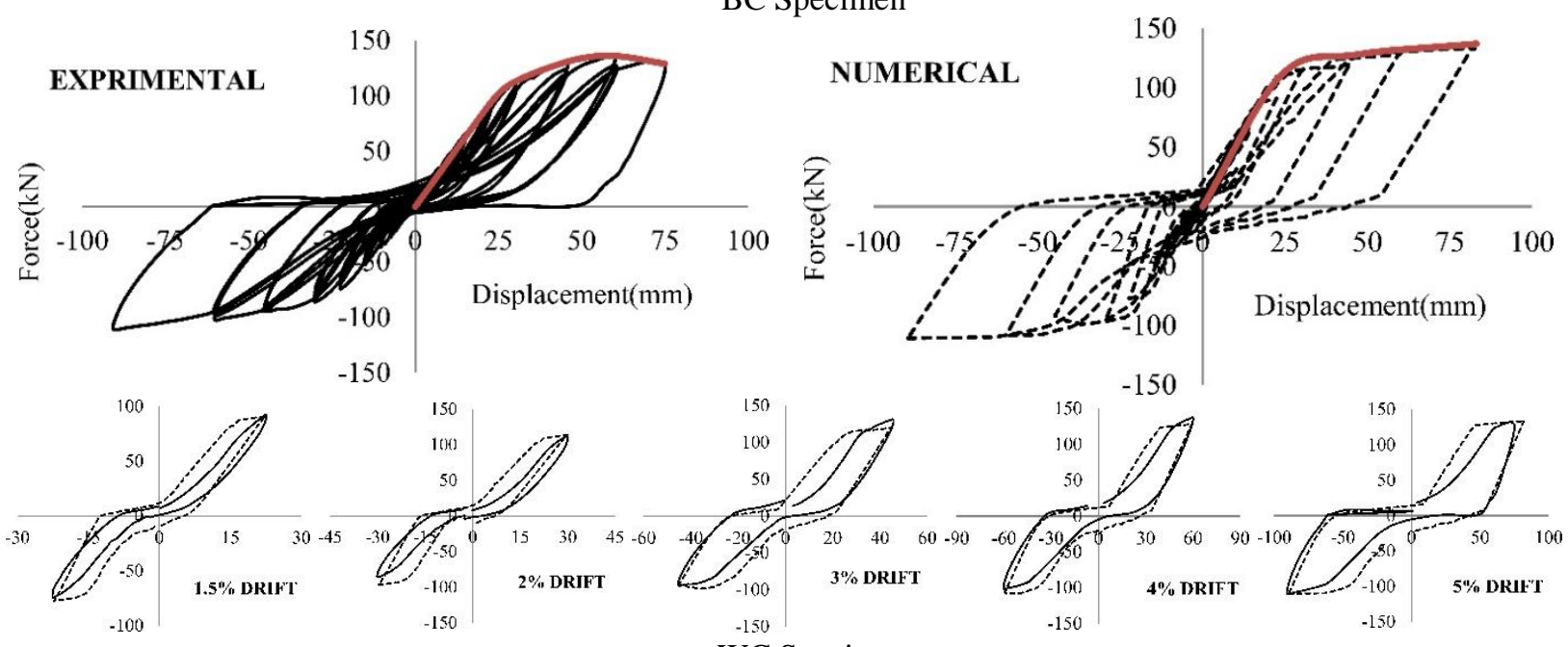

WC Specimen
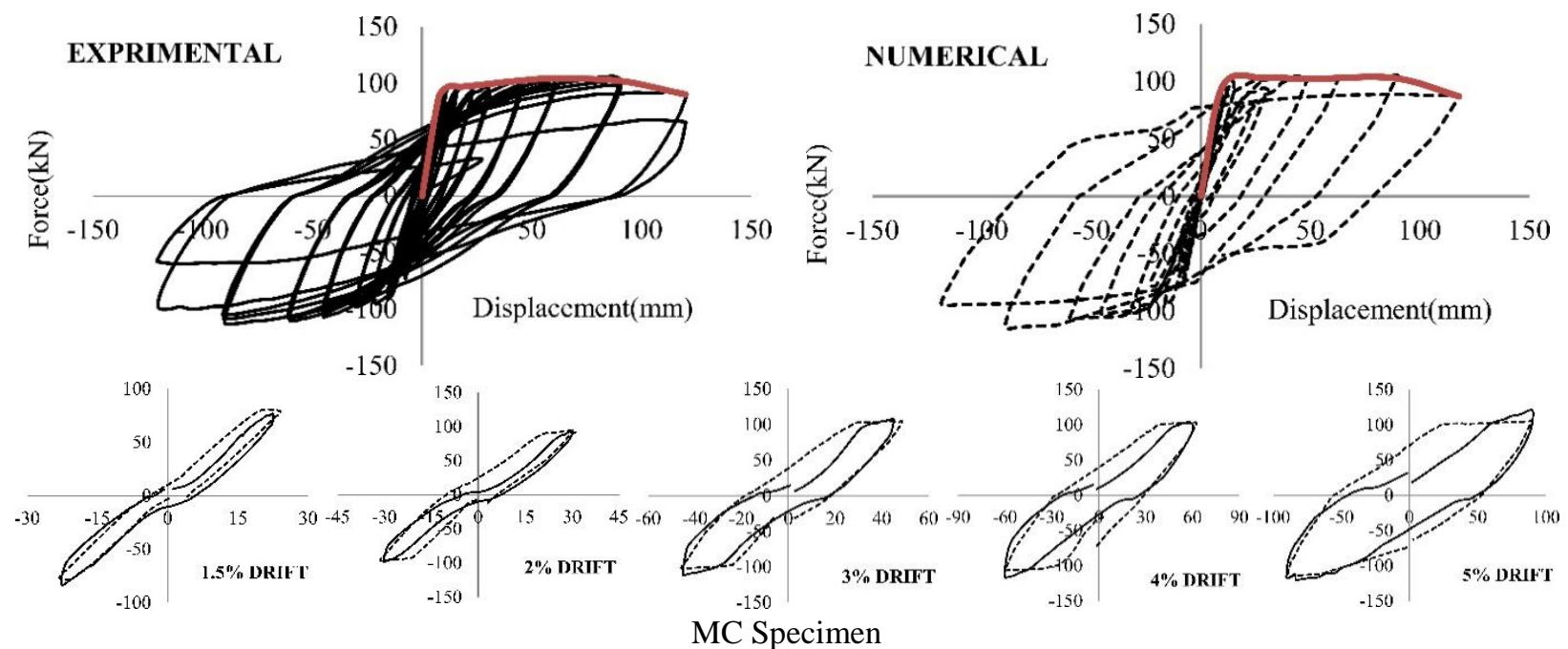

Fig. 7 Hysteresis curve of specimens 


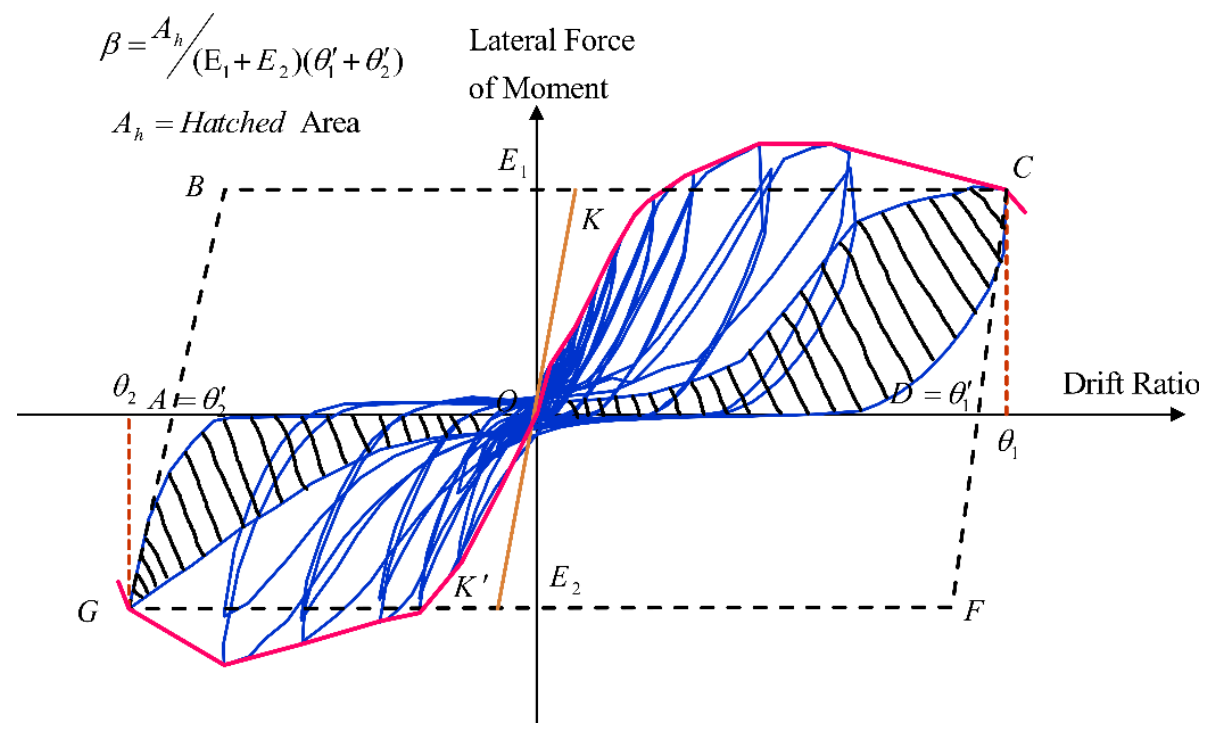

Fig. 8 Relative energy dissipation ratio concept
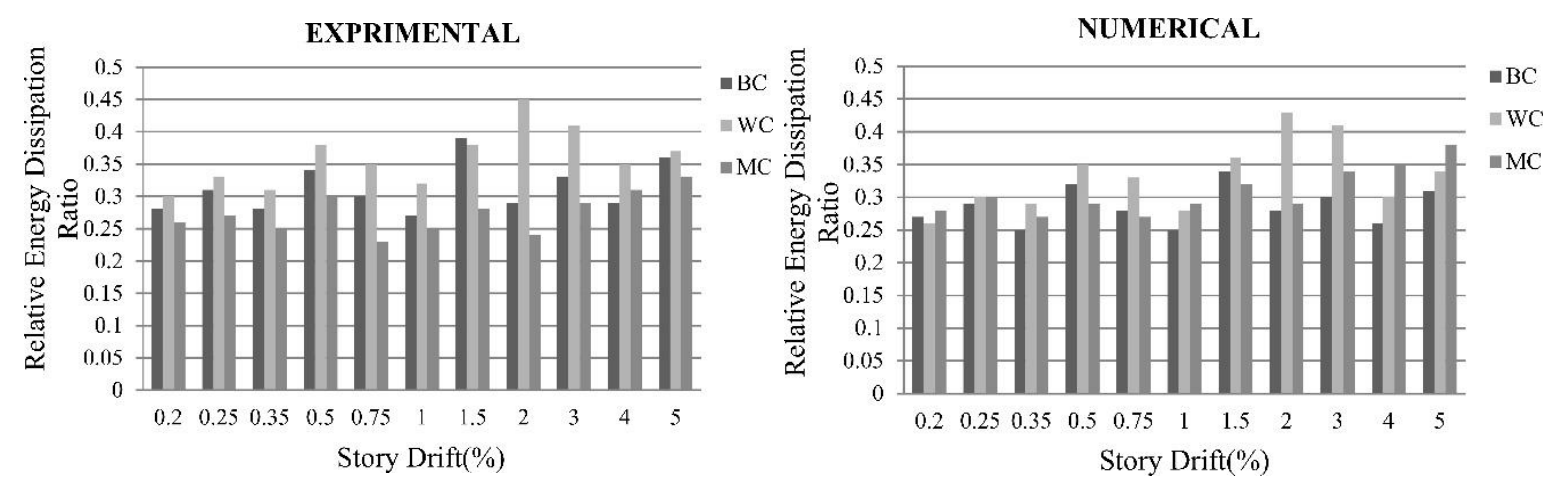

Fig. 9 Relative energy dissipation of specimens

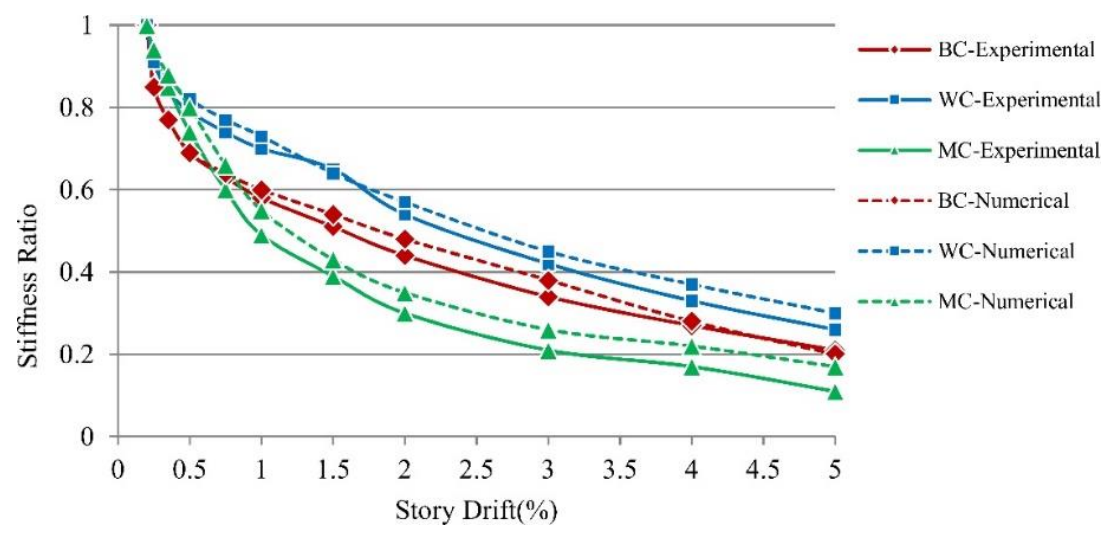

Fig. 10 Stiffness degradation of specimens 


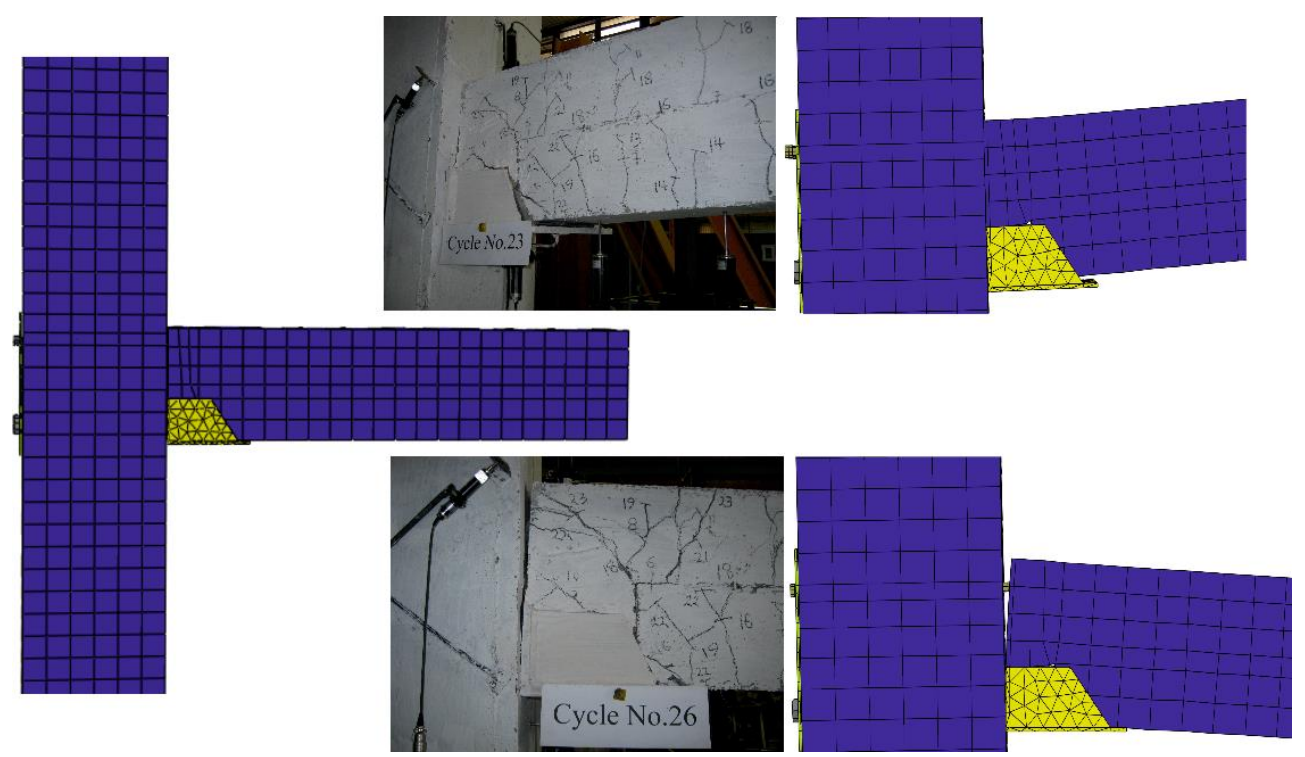

Fig. 11 Deformation shapes in contact points in FEM and corresponding behavior in test
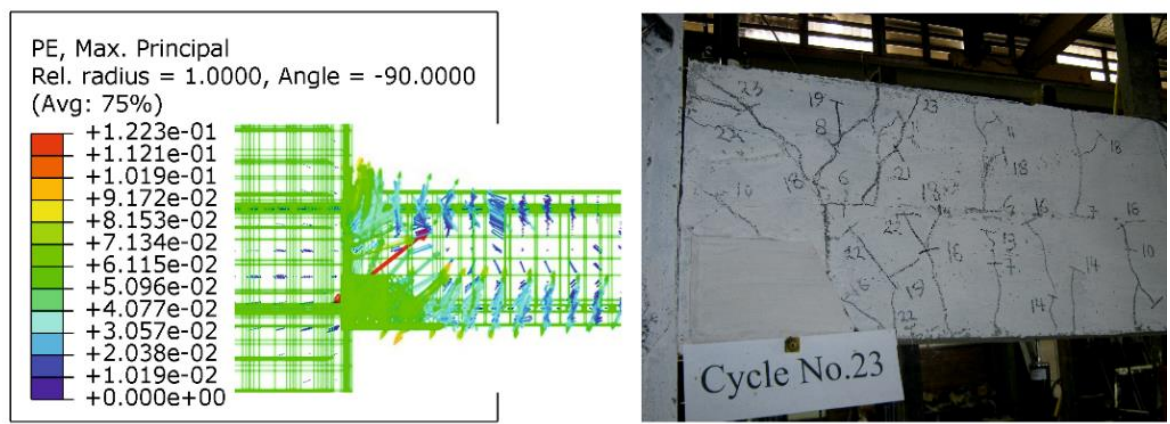

BC Specimen

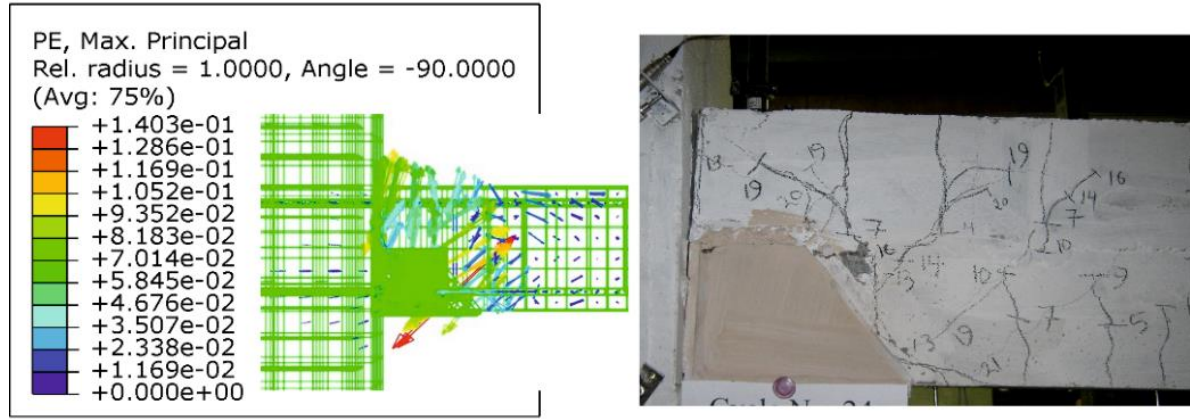

WC Specimen
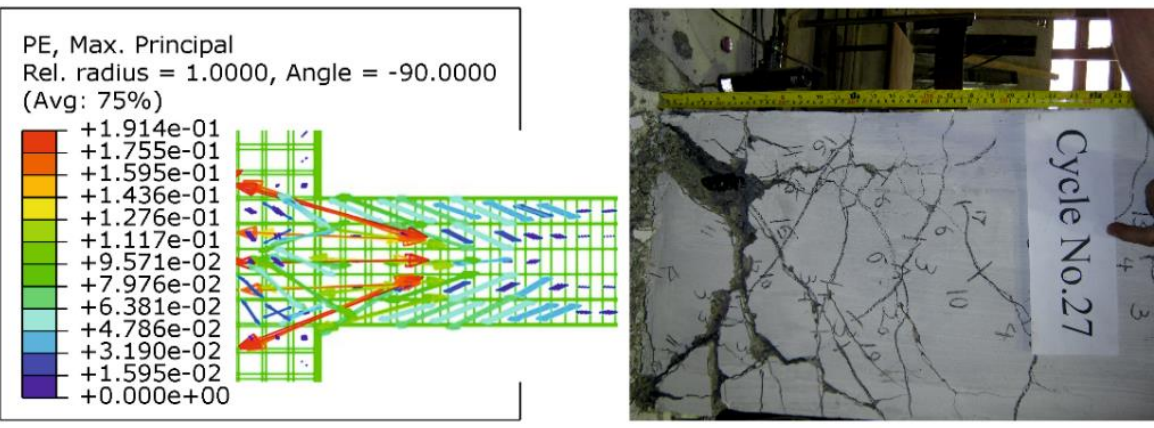

MC Specimen

Fig. 12 Comparison of crack pattern in specimens and prediction of cracks in finite element models 
Table 1 Mechanical property of materials

\begin{tabular}{|c|c|c|c|c|}
\hline parts & Material & $f^{\prime}{ }_{c}(\mathrm{MPa})$ & $f_{y}(\mathrm{MPa})$ & $f_{u}(\mathrm{MPa})$ \\
\cline { 1 - 5 } In situ- concrete & \multirow{2}{*}{ Concrete } & 35 & - & - \\
\cline { 1 - 4 } Precast concrete & steel & - & 240 & 370 \\
\cline { 1 - 4 } Linkage & steel & & 400 & 600 \\
\hline Reinforcement & \multicolumn{3}{|l}{} \\
\hline
\end{tabular}

Table 2 Mechanical characteristics of specimens

\begin{tabular}{|c|c|c|c|c|c|c|c|c|c|}
\hline \multicolumn{2}{|c|}{ Specimen } & $\begin{array}{c}\text { Maximum } \\
\text { strength }(\mathrm{kN})\end{array}$ & $\begin{array}{c}\text { Ultimate } \\
\text { strenght }(\mathrm{kN})\end{array}$ & $\begin{array}{c}\delta_{y} \\
(\mathrm{~mm})\end{array}$ & $\begin{array}{c}\delta_{u} \\
(\mathrm{~mm})\end{array}$ & $\alpha$ & $\begin{array}{c}I S \\
\text { (ton/m) }\end{array}$ & $\mu$ & $\Omega$ \\
\hline \multirow{2}{*}{ BC } & Experimental & 128 & 128 & 22.8 & 78 & 1 & 380 & 3.42 & 1.74 \\
\cline { 2 - 12 } & Numerical & 134 & 134 & 22.85 & 80 & 1 & 430 & 3.5 & 1.82 \\
\hline \multirow{2}{*}{ WC } & Experimental & 136 & 129 & 27.8 & 75 & 0.95 & 413 & 2.7 & 1.85 \\
\cline { 2 - 11 } & Numerical & 137 & 137 & 29.1 & 83 & 1 & 458 & 2.85 & 1.87 \\
\hline \multirow{2}{*}{ MC } & Experimental & 104 & 102 & 19.35 & 120 & 0.88 & 1090 & 6.2 & 1.41 \\
\cline { 2 - 11 } & Numerical & 103 & 102 & 18.7 & 118 & 0.98 & 980 & 6.3 & 1.40 \\
\hline
\end{tabular}

Mojtaba Fathi was born in Kermanshah. He received his BS degree from Tehran University and his MS and $\mathrm{PhD}$ degrees from Tarbiat Modares University of Tehran in 1997 and 2004, respectively. At present, he works as an Assistant Professor at the Department of Civil Engineering in Razi University.

Mahdi Parvizi was born in Kermanshah. At the moment, he is a PhD student of Structural Civil Engineering at Razi university. He got his BS degree from Jondi Shapoor University of Dezfool in 2010, and his MS degree from Amir Kabir University in 2012. 